NBER WORKING PAPER SERIES

\title{
UNEMPLOYMENT AND PRODUCTIVITY IN THE LONG RUN: THE ROLE OF MACROECONOMIC VOLATILITY
}

\author{
Pierpaolo Benigno \\ Luca Antonio Ricci \\ Paolo Surico \\ Working Paper 16374 \\ http://www.nber.org/papers/w16374
NATIONAL BUREAU OF ECONOMIC RESEARCH
1050 Massachusetts Avenue
Cambridge, MA 02138
September 2010

We are grateful to Lawrence Ball, Olivier Blanchard, Renato Faccini, Giovanni Favara, Jordi Galì, Andrew Levin, Francesco Nucci, Chris Pissarides, Pau Rabanal, Valerie Ramey, David Romer, Julio Rotemberg, Francisco Ruge-Murcia, Giovanna Vallanti, Mark Watson, three anonymous referees, and conference participants at NBER Monetary Economics Meeting, the invited panel session on monetary policy of the European Economic Association Congress in Glasgow, the Sveriges Riksbank conference on "The Labor Market and the Macroeconomy", the Università degli Studi di Roma "La Sapienza" Workshop on "Advancements in Macroeconomic Theory and Policy", the University of Nuremberg on "Labor Market Institutions and Macroeconomic," and the seminar participants at Banca d'Italia, EIEF, Ministero del Tesoro, Università Ca'Foscari Venezia, Universitat Autonoma de Barcelona, for helpful discussions. Federica Romei and Marola Castillo have provided excellent research assistance. Pierpaolo Benigno acknowledges financial support from an ERC Starting Independent Grant. The views in this paper are those of the authors and do not necessarily reflect the views of the IMF, or IMF policy, nor the views of the National Bureau of Economic Research.

NBER working papers are circulated for discussion and comment purposes. They have not been peerreviewed or been subject to the review by the NBER Board of Directors that accompanies official NBER publications.

(C) 2010 by Pierpaolo Benigno, Luca Antonio Ricci, and Paolo Surico. All rights reserved. Short sections of text, not to exceed two paragraphs, may be quoted without explicit permission provided that full credit, including $\odot$ notice, is given to the source. 
Unemployment and Productivity in the Long Run: The Role of Macroeconomic Volatility Pierpaolo Benigno, Luca Antonio Ricci, and Paolo Surico

NBER Working Paper No. 16374

September 2010, Revised November 2013

JEL No. E0,E20,E40

\section{ABSTRACT}

The paper presents a new empirical regularity between the volatility of productivity growth and long-run unemployment, for a given level of long-run productivity growth. A theoretical framework based on asymmetric real wage rigidities is shown to have the potential to rationalize this finding. The model tends to fit U.S. long-run unemployment better than a specification based on long-run productivity growth only, especially during the Great Moderation and the Great Recession.

Pierpaolo Benigno

Dipartimento di Economia e Finanza

Luiss Guido Carli

Viale Romania 32

00197 Rome

ITALY

pierpaolo.benigno@eief.it

Luca Antonio Ricci

International Monetary Fund

Research Department

700 19th Street, N.W.

Washington, D.C. 20431

1ricci@imf.org
Paolo Surico

London Business School

Regent's Park

NW1 4SA

London (United Kingdom)

psurico@london.edu 


\section{Introduction}

The recent financial crisis has brought unemployment back to the front page of policy and academic research agendas. An unusual feature of the most recent U.S. experience is that the persistent rise in unemployment has not been associated with a persistent fall in productivity growth. This pattern is interesting because it contrasts with a more standard negative relationship between low-frequency movements in unemployment and productivity growth over most of the post-WWII period, with notable exceptions during the second half of the 1980s and the late 2000s. ${ }^{1}$ (This pattern is visible in the first column of Figure 1 using methods described below. ${ }^{2}$ )

This paper shows how this apparent inconsistency can be resolved by uncovering the presence of an additional relationship. Indeed, the second column of the figure reveals another intriguing feature of the data: there exists a positive association between longrun unemployment and the variance of productivity growth. The latter relationship seems particularly strong during the aforementioned periods in which the first relation is weak: the second half of the 1980s and the late 2000s. For instance, the Great Moderation in the volatility of productivity growth coincides with a sharp fall in the trend of unemployment. In the econometric analysis below, we confirm that this tight positive relationship holds over and above the negative link between unemployment and productivity growth in the long-run, thereby suggesting a key effect of macroeconomic volatility on unemployment.

Consistent with the prima facie evidence in Figure 1 and the econometric evidence in the rest of the paper, we present a simple theoretical framework in which the trend in unemployment is explained by both the trend and the variance of productivity growth. The key mechanism that explains these relationships rests on the assumption that real wages, and more broadly real marginal costs, adjust upward less costly than they adjust downward.

Asymmetric real wage rigidities generate two testable predictions in our framework. First, for a given volatility of productivity growth, a slowdown in long-run productivity growth generates a significant rise in long-run unemployment. This is because, when growth is lower, productivity reductions will run more frequently into the downward wage rigidity constraint, thus making it more likely that real revenues will fall relative to costs, which in turn would force firms to reduce labor demand in order to protect profits. Second, for a given long-run productivity growth, a higher volatility raises the probability of a significant adverse shock that makes the downward wage constraint binding, thus leading

\footnotetext{
${ }^{1}$ The terms long-run, trend, mean and low-frequency are used interchangeably throughout the paper.

${ }^{2}$ Results are robust to using ten-year windows, the Hodrick-Prescott or Christiano-Fitzgerald filters.
} 

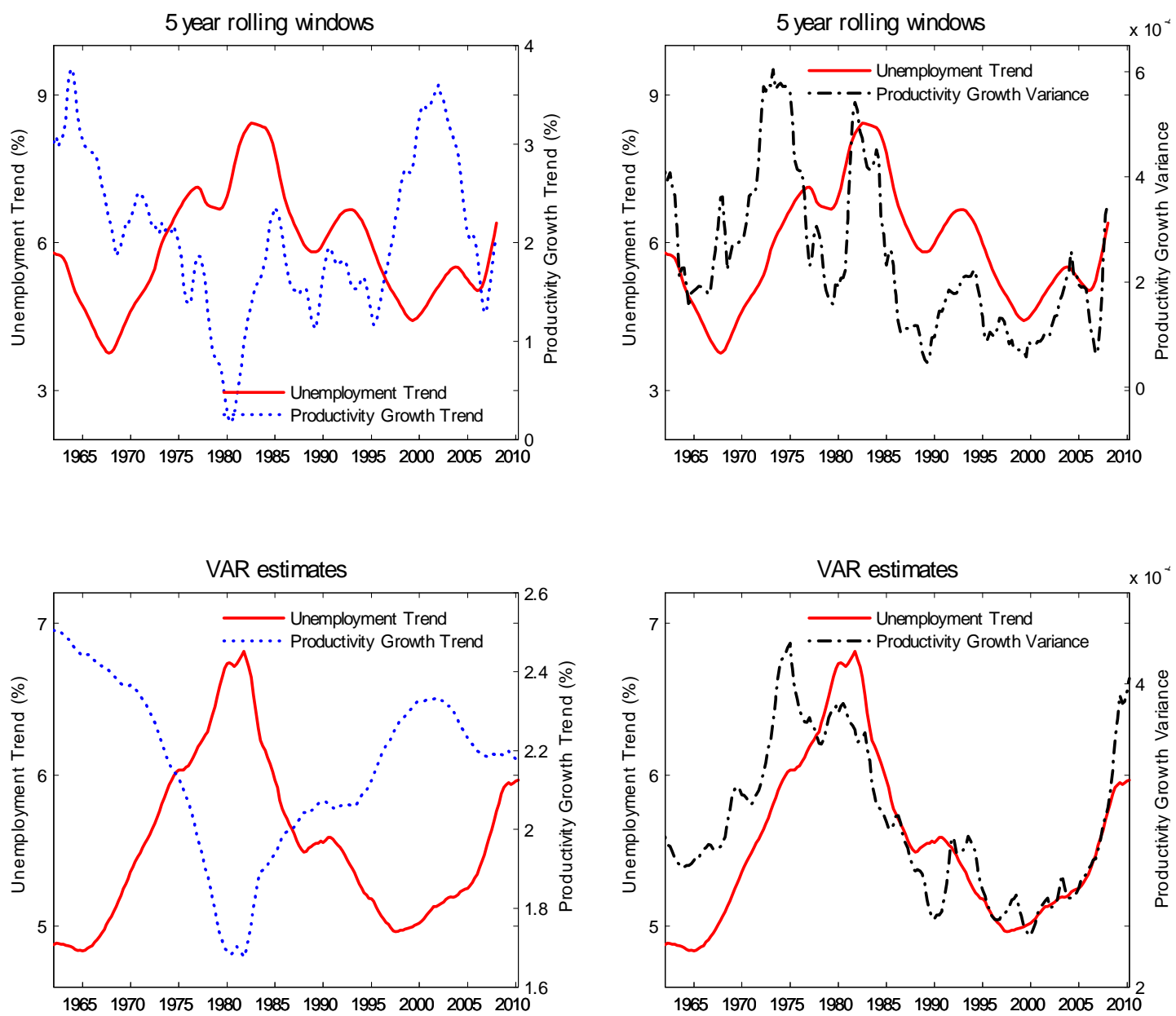

Figure 1: Long-run unemployment, long-run productivity growth and variance of productivity growth for the U.S., computed using five-year rolling windows for the charts in the first row and the time-varying VAR described in the Appendix for the charts in the second row. 
to higher long-run unemployment. Conversely, even when the trend in productivity growth is low, a decline in its volatility reduces these risks and causes the unemployment trend to fall.

The paper also presents empirical evidence on U.S. data consistent with the implications of the theoretical model. First, the low-frequency movements of productivity growth and of the variance of productivity growth are significant determinants of the low-frequency movements of unemployment. This holds true even when we control for changes in the demographic composition of the labor force. Second, specifications that include a measure of productivity growth volatility are associated with a significant improvement in the goodness of fit relative to a linear specification in long-run productivity growth only. This is consistent with the notion that macroeconomic volatility played an important role during the fall in long-run unemployment over the 1980s and its rise during the late 2000s, as visible in Figure 1. Indeed, these two episodes cannot be fully explained by low frequency movements of productivity growth only. Our finding therefore also contributes to the recent evidence on the macroeconomic effects of measures of volatility and uncertainty (see Bloom, 2009, Baker, Bloom and Davis, 2012, and Fernandez-Villaverde et al. 2011).

A first motivation for our analysis comes from a number of empirical papers on aggregate data, including Bruno and Sachs (1985), Phelps (1994), Blanchard et al. (1995), Blanchard and Wolfers (2000), Staiger, Stock, and Watson (2001) Pissarides and Vallanti (2007), and Shimer (2010), which show time-series and cross-country evidence in favor of a negative relationship between unemployment and productivity growth at low frequencies. In a related theoretical study, Ball and Mankiw (2002) suggest a possible rationale for the negative relationship between unemployment and productivity "resting on the idea that 'wage aspirations' adjust slowly to shifts in productivity growth", as "workers come to view the rate of real wage increase that they receive as normal and fair and to expect it to continue". 3

A second motivation arises from a large body of literature supporting downward real wage rigidities. A cursory observation at U.S. real wages and unemployment over the past few decades in Figure 2 shows that real wages do not decline even when unemployment rises significantly; this feature is particularly striking during the recent recession. The

\footnotetext{
${ }^{3}$ In traditional labor search models, the relationship between productivity and unemployment is generally uncertain, as it depends mostly on the extent to which jobs can be upgraded or need to be eliminated when new technology arises (Mortensen and Pissarides, 1998). If firms cannot embody the new technology into existing jobs, higher productivity would lead to job destruction and higher unemployment (Aghion and Howitt, 1994). If productivity increases for all existing jobs, demand for labor would increase and unemployment would decline (Pissarides, 2000, Pissarides and Vallanti, 2007).
} 


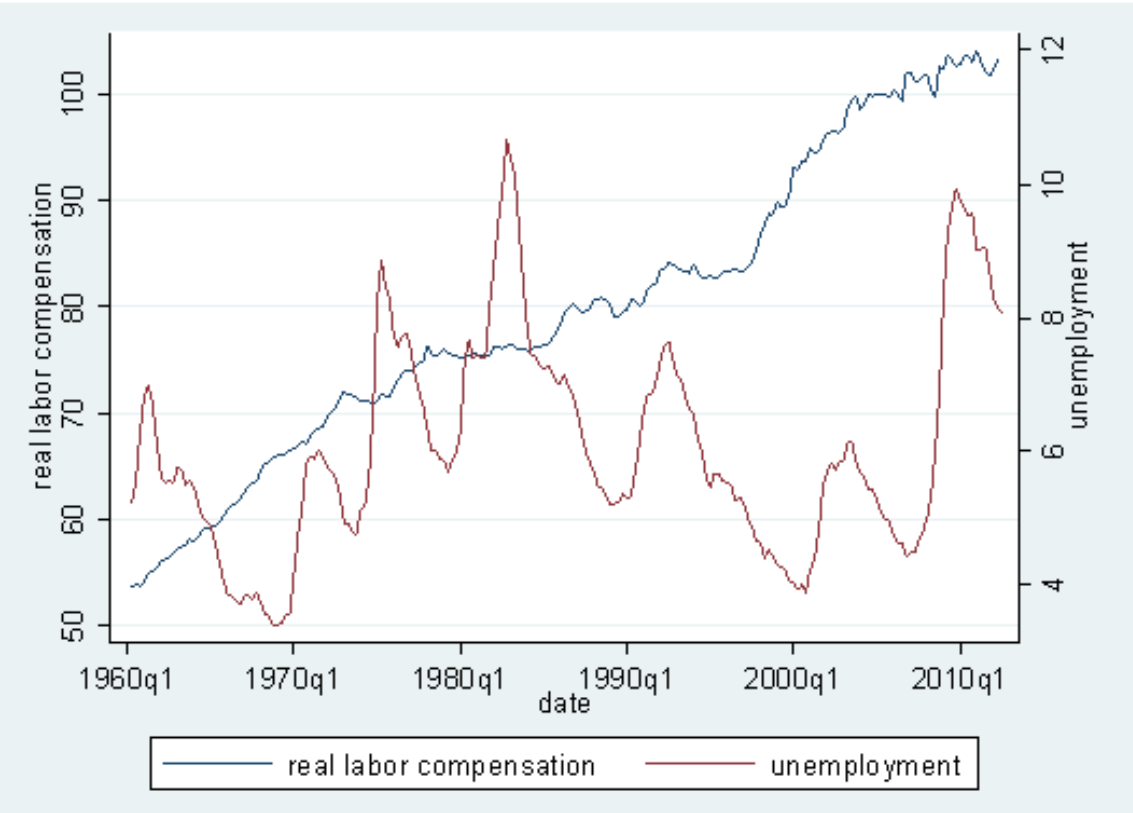

Figure 2: U.S. unemployment rate on the right axis; U.S. nonfarm business sector real compensation per hour (SA, 2005=100) on the left axis, source: Bureau of Labor Statistics.

"existence of real wage rigidities has been pointed to by many authors as a feature needed to account for a number of labor market facts" (Blanchard and Gali, 2007, p.36). Indeed, a recent literature, popularized by Shimer (2005), Hall (2005), Gertler and Trigari (2009), Barnichon (2010) and Blanchard and Gali (2010), emphasizes that real wage rigidities contribute to explain labor-market dynamics at business cycle frequencies such as the high volatility of employment and vacancies, as well as the low volatility of real wages and jobless recoveries. ${ }^{4}$ Our paper contributes to this literature by showing that asymmetric real rigidities can also account for unemployment dynamics at low frequencies, in a way that depends on macroeconomic volatility.

The hypothesis of downward real wage rigidities appears to receive empirical support in numerous studies using survey data, particularly in recent years when these surveys have become more widely available. Several papers employ large panels of advanced economies, including Babecky et al. (2010), Dickens et al. (2008), Du Caju et al. (2009), Fabiani et al. (2010), Fagan and Messina (2009), Holden and Wulfsberg (2009), and Messina et al. (2010). Regarding specific advanced economies, Christofides and Nearchou (2010) and Christofides and $\mathrm{Li}$ (2005) find strong micro evidence of downward real wage rigidities

\footnotetext{
${ }^{4}$ Pissarides (2009) offers a critical appraisal of wage stickiness as a driver of the cyclical volatility of unemployment in search models.
} 
in Canada, arguing (in the second paper) that " $90 \%$ of expected inflation is built into a contract ex ante and over $62 \%$ of unexpected inflation in the previous contract is built into the current notional wage adjustment." Bauer et al. (2007) find that in Germany $30 \%$ to $70 \%$ of wages settings are subject to downward real wage rigidities; Devicienti et al. (2007) show that in Italy that proportion varies between $45 \%$ to $65 \%$; Barwell and Schweitzer (2007) suggest that in the UK downward real wage rigidities affect on average $41 \%$ of the workers.

Our work also complements an important literature which highlighted the relevance of demographic changes in labor force participation in explaining low-frequency movements of unemployment (see Shimer, 1998, and Francis and Ramey, 2009, among others). We show that the finding of a significant role for the trend and the variance of productivity growth in explaining the trend in unemployment is robust to controlling for movements in the share of young workers in the labor force as well as to using the measure of "genuine" unemployment that Shimer (1998) argues to be unaffected by demographics influences.

Finally, Hairault et al. (2010) show that a matching model generates the reducedform prediction of a positive link between macroeconomic volatility and labour market outcomes. Interestingly, the authors report a negative association between unemployment and total factor productivity as well as a positive association between unemployment and the squared values of total factor productivity in an annual panel of 20 OECD countries over the period 1982-2003. While we share the emphasis on the role of productivity growth variance, the theoretical mechanism in this paper is rather different and the inference is drawn upon time series evidence for the United States.

The paper is organized as follows. Section 2 presents the model and shows the mechanism through which asymmetric real wage rigidities generate a long-run relationship between unemployment, productivity growth and its volatility. Section 3 confronts the predictions of the model with the time series properties of U.S. data and present evidence of a positive relationship between unemployment and productivity growth trends as well as a negative association between long-run unemployment and productivity growth variance. Section 4 assesses the robustness of our findings to splitting the sample around the onset of the great moderation, to using total factor productivity (rather than labour productivity) and to controlling for demographic trends. Section 5 concludes. The appendices provide details of the empirical models. 


\section{The theoretical framework}

In this section, we show that introducing a simple form of asymmetric real wage rigidities into an otherwise standard macroeconomic framework allows us to capture key macroeconomic implications for unemployment, while grounding them better on the empirical evidence discussed in the previous section. A richer general equilibrium model with downward real wage rigidities is presented in our working-paper version, Benigno, Ricci, and Surico (2010). Consider a neoclassical model with profit-maximizing firms having a production function $Y_{t}=A_{t} L_{t}^{\alpha}$, where $Y_{t}$ is output produced, $A_{t}$ is productivity and $\alpha$ (with $0<\alpha<1$ ) measures decreasing return to scale. Given this technology, the labor demand schedule has the form

$$
\ln L_{t}^{d}=\frac{1}{1-\alpha}\left(\tilde{w}+\ln A_{t}-\ln w_{t}\right),
$$

where $L_{t}^{d}$ is the demand of labor and $\tilde{w} \equiv \ln \alpha$. High values of the real wage reduce the demand of labor because they push up marginal costs of firms. ${ }^{5}$ On the contrary an increase in productivity raises the marginal productivity of labor and, for given wages, simply allows firms to hire more.

A standard labor-supply schedule can be derived from the first-order conditions of optimizing households with respect to labor and consumption. With separable isoelastic utility, the labor supply schedule can be written in a simple exact log-linear form

$$
\ln L_{t}^{s}=\eta\left(\ln w_{t}+\ln \lambda_{t}\right)
$$

where $\eta$ measures the Frisch elasticity of labor supply and $\lambda_{t}$ is the marginal utility of consumption. Workers are willing to supply more labor, $L_{t}^{s}$, for higher real wages. Under log-consumption utility (which is required to deliver a balance-growth path), the marginal utility of consumption can be written as $\lambda_{t}=Y_{t}^{-1}=A_{t}^{-1}\left(L_{t}^{d}\right)^{-\alpha}$, taking into account that consumption is equal to output in equilibrium. We are also implicitly assuming that employment is always determined by demand and therefore we evaluate $\lambda_{t}$ given the amount of labor effectively employed.

Following Galì (2011), unemployment can be naturally defined as the excess of supply of workers with respect to labor demand, at a given wage (in logs)

$$
u_{t}=\ln L_{t}^{s}-\ln L_{t}^{d}
$$

\footnotetext{
${ }^{5}$ In our model, the real wage and productivity are the only variables influencing the real marginal costs and therefore labor demand. In models of unemployment through search and matching frictions, Krause and Lubik (2007), Blanchard and Galì (2010) and Hairault et al. (2010) have shown that search frictions affect directly the real marginal costs and can contribute to their variation.
} 
Using this result, we can combine (1) and (2) into (3) to obtain

$$
u_{t}=\gamma\left(\ln w_{t}-\ln A_{t}-\bar{w}\right)
$$

where $\bar{w} \equiv \tilde{w}(1+\alpha \eta) / \gamma$ and $\gamma \equiv(1+\eta) /(1-\alpha)$. The above equation shows that unemployment fluctuations are driven by the differences between the real wage and productivity.

In a neoclassical model, wages perfectly adjust to clear labor market so that labor demand is always equal to supply. Unemployment is equal to zero, employment is constant and equal to its frictionless level and real wages always catch up with productivity, i.e. $w_{t}^{f}=A_{t} \exp (\bar{w})$. In particular, let's assume that the log of productivity is distributed as a Brownian motion with drift $g$ and variance $\sigma^{2}$ :

$$
d \ln A_{t}=g d t+\sigma d B_{t}
$$

in which $B_{t}$ denotes a standard Brownian motion with zero drift and unit variance.

In this case, real wages inherit the same trend as productivity in equilibrium, while long-run unemployment does not exhibit a trend. ${ }^{6}$ Clearly, so far, this framework ignores the key empirical evidence on wage rigidities discussed in the previous section, as it assumes that wages adjust immediately to any productivity movements leaving no room for productivity to influence unemployment, both in the short run and in the long run.

Even allowing for real distortions in the form of some monopoly power in the labor market, as in Dunlop (1944), would not alter this result. Such monopoly power would add a constant component to unemployment $(\bar{u})$, thus entailing a modification of the above equation (4) as follows

$$
u_{t}=\bar{u}+\gamma\left(\ln w_{t}-\ln A_{t}-\bar{w}\right)
$$

where, as in Galì (2011), $\bar{u}$ represents the natural rate of unemployment. When wages are fully flexible, unemployment will continue to depend only on $\bar{u}$ in both the short and the long run, and not on productivity.

We now argue that real wage rigidities would alter this result and offer a role for productivity in (6). But whether they are symmetric or asymmetric would make a crucial difference.

Let's first consider the case of symmetric real wage rigidities. Among others, Ball and Mankiw (2002) and Ball and Moffit (2002) consider that wages are slow to catch-up with productivity movements, so that productivity would be reflected into movements of

\footnotetext{
${ }^{6}$ We could also allow $g$ and $\sigma$ to vary over time through stationary stochastic processes. However, this would come at the cost of analytical tractability without overturning our results. Indeed our focus is on the effects that the long-run means of $g$ and $\sigma$ have on long-run unemployment.
} 
unemployment. This is clearly visible in (6): if wages do not catch up completely with productivity, productivity itself can affect the unemployment rate, accounting for part of the empirical evidence described in the previous section.

However, this explanation presents some shortcomings. First, for productivity to affect unemployment in the long-run, there should be some incomplete catch-up of real wages to productivity growth even in the long run which is somewhat hard to justify. Moreover, this explanation gives no role for the volatility of productivity growth to affect unemployment. This can be easily seen in (6) by considering the special case in which the trend in productivity growth is close to zero and real wages are completely rigid (both upward and downward): positive and negative shocks to productivity would imply symmetric effects on employment and unemployment in such a way that average unemployment will not be affected by higher or lower volatility.

Consider now the case of asymmetric real wage rigidities (wages adjust more easily upward rather than downward) and in particular let us first focus on the limiting case in which wages never fall. The top chart of Figure (3) plots a possible path for the level of productivity with some trend and volatility. In the same graph, a path of real wages consistent with complete downward inflexibility is shown. ${ }^{7}$ The bottom chart in the Figure plots the equilibrium unemployment rate consistent with (6). Following positive productivity developments, real wages can rise to match productivity, and the labor market clears with unemployment at the natural rate. However, as soon as productivity declines, workers are not willing to lower real wages and firms demand less labor, and the excess of supply of labor at that wage translates into higher unemployment. The asymmetric adjustment in real wages translates into an asymmetric response of unemployment to productivity shocks. Recessions are much worse than expansions for unemployment, simply because a negative shock to productivity would translate into higher unemployment given the resistance of real wages to fall. On the contrary, a positive shock to productivity would be compensated by high real wages without delivering higher employment.

Figure (3) can also help describing the intuition for the long run relationship. We can loosely think of long-run unemployment as the average of unemployment over all the horizon shown in the figure. First, imagine that productivity follows a path with a higher trend. In this case declines in productivity, requiring a negative wage adjustment, are less likely and therefore the average unemployment computed over the full horizon is smaller. The model would be consistent with the negative relationship found in the data between trends in productivity growth and long-run unemployment. Second, imagine, again in

\footnotetext{
${ }^{7}$ The variable $w_{t}$ is appropriately scaled by $\exp (\bar{w})$ in the Figure to align it with the level of productivity. We thank one of the referees for suggesting this Figure.
} 


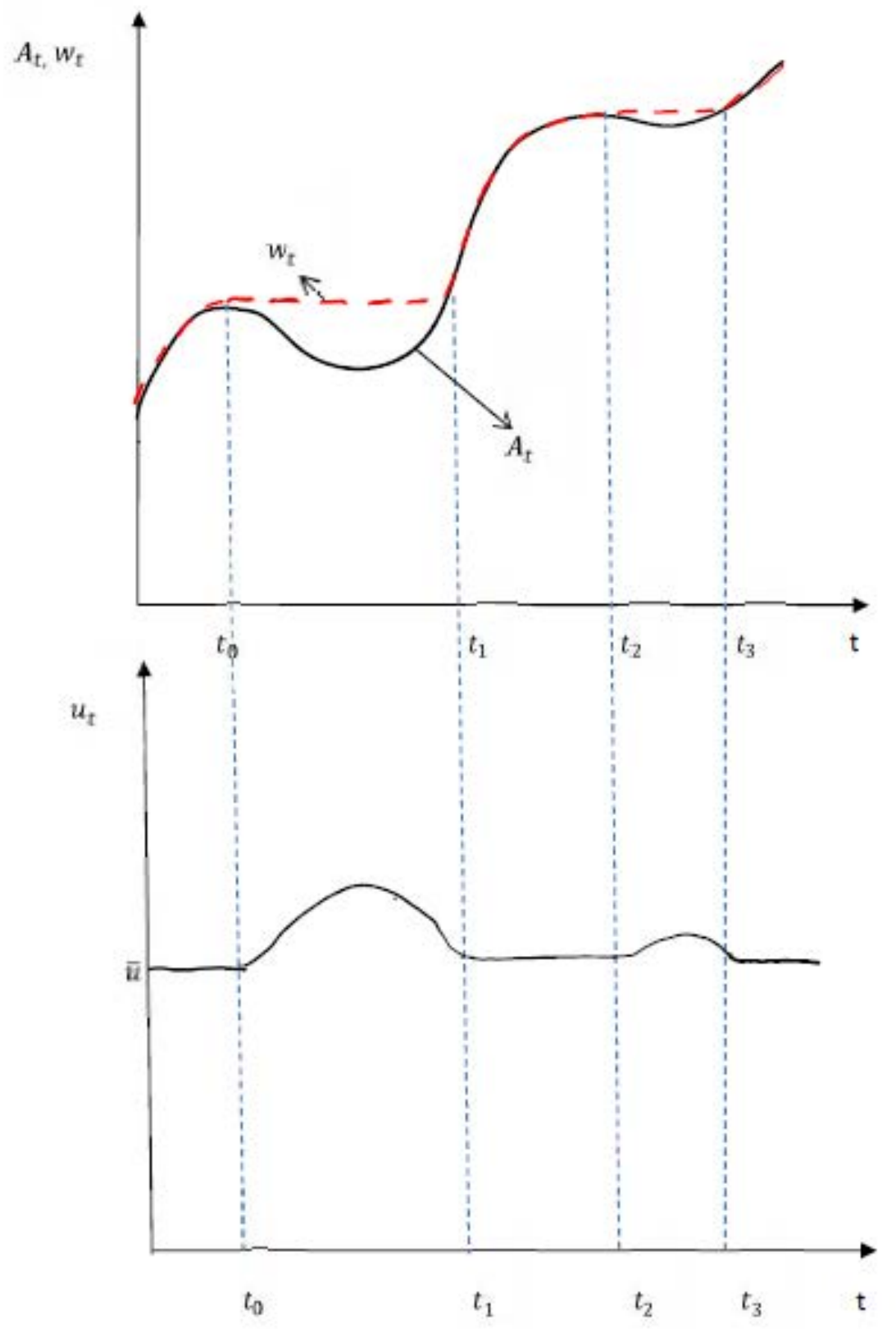

Figure 3: The top chart illustrates a possible path of the level of productivity, $A_{t}$, and of real wages, $w_{t}$. The latter variable is scaled by the factor $\exp (\bar{w})$ and mimick productivity when $w_{t}>w_{t-1}$ otherwise it remains constant at previous level because of the downwardrigidity constraint. In the bottom chart we plot the equilibrium level of unemployment resulting from equation (6). 
Figure (3), a path for productivity with a higher volatility without changing the trend. In this case, negative cycles are amplified and recessions are much deeper. On average unemployment is higher over the full period, which explains the positive relationship between unemployment and the volatility of productivity growth found in the data at low frequencies. ${ }^{8}$ The model with asymmetric rigidities can at the same time address the shortcomings of the model with symmetric rigidities as well as deliver new and interesting results.

To develop this intuition formally, assume that real wages are constrained in their adjustment by the following limit

$$
d \ln w_{t} \geq-\kappa \cdot d t
$$

i.e. real wages can move up freely, but they are constrained not to fall by more than $\kappa$ percent. In other words, real wages are not necessarily completely downward rigid: there are downward real wage rigidities of varying degree in our model, so that nominalwage growth can also fall below price inflation. This implies that whenever there are bad productivity shocks requiring real wages to fall by more than $\kappa$ percent, real wages would only adjust downward by $\kappa$ percent and unemployment would arise. Instead when shocks are positive, or moderately negative so as to require a movement in real wages that does not run into the constraint, real wages are assumed to adjust perfectly to productivity as in the frictionless model, $w_{t}=w_{t}^{f}=A_{t} \exp (\bar{w})$, and therefore the labor market clears completely. ${ }^{9}$ Since it is always the case that wages are bounded below by the flexiblewage level, i.e. $w_{t} \geq w_{t}^{f}$, equation (6) implies that $\bar{u} \leq u_{t}<\infty$. Moreover, since $\ln A_{t}$ follows a Brownian motion with drift $g$ and standard deviation $\sigma$, equation (6) implies that unemployment, $u_{t}$, is going to follow a regulated Brownian motion. ${ }^{10}$ Indeed, it is a

\footnotetext{
${ }^{8}$ Figure (3) suggests that in the short-run unemployment is negatively related with productivity during downturns and uncorrelated during expansions. If volatility is lower, for the same trend, downturns are less likely and then an econometrician would detect a lower correlation between unemployment and productivity over a sample. Figure (3) also suggests that there is not a clear negative or positive relationship, in the short run, between the level of unemployment and productivity growth.

${ }^{9}$ More generally, as discussed in the working-paper version Benigno, Ricci and Surico (2010), optimizing wage setters would choose an adjustment rule that tries to minimize the inefficiencies of downward real wage inflexibility. As a consequence, they would refrain from excessive real wage increases when favorable shocks require upward adjustment as explained by Elsby (2009). In particular, in the model of Benigno, Ricci and Surico (2010), wage setters will choose a wage below, but proportional to, the flexible wage, thus pushing current employment above the flexible-case level. In the current Figure (3) there will be periods in which unemployment is below the natural rate. This mechanism would provide additional interesting features to the model which, however, would not alter the sign of the long-run relationships between unemployment, productivity growth and its volatility highlighted in the text. For more details, we refer the reader to Benigno, Ricci and Surico (2010).

${ }^{10} \mathrm{~A}$ regulated Brownian motion is a brownian motion with a reflecting barrier. Within the boundaries,
} 
Brownian motion with mean $-\gamma(g+\kappa)$ and variance $\gamma^{2} \sigma^{2}$ when the constraint on wages holds with equality, i.e. when $d \ln w_{t}=-\kappa \cdot d t$, while it has a reflecting barrier at $\bar{u}$ when wages adjust upward, i.e. when $d \ln w_{t}>-\kappa \cdot d t$. The probability distribution function for such process can be computed at each point in time. ${ }^{11}$ Standard results assure that this probability distribution converges to an equilibrium distribution for $t \rightarrow \infty$, when the drift of the Brownian motion of $u_{t}$ is negative, i.e. $g+\kappa>0$ so that $-\gamma(g+\kappa)<0$. In this case, it can be shown that the long-run cumulative distribution of $u_{t}$, denoted with $P(\cdot)$, is given by

$$
P\left(u_{\infty} \leq z\right)=1-e^{\frac{2(\kappa+g)}{\gamma \sigma^{2}}(z-\bar{u})}
$$

for $\bar{u} \leq z<\infty$ where $u_{\infty}$ denotes the long-run equilibrium level of unemployment.

The long-run mean of unemployment would then be

$$
E\left[u_{\infty}\right]=\bar{u}+\frac{1}{2} \gamma \cdot\left(\frac{\sigma^{2}}{g+\kappa}\right)
$$

which shows that a determinant of the long-run average unemployment is the ratio between the volatility of productivity growth and its mean. The latter is adjusted for the degree of downward wage flexibility.

Results are consistent with the intuition underlined above and with the empirical evidence presented in the introduction. First, the higher is the volatility of productivity growth, the higher is the long term unemployment rate. Second, the lower is the trend in productivity growth, the higher is the long term unemployment rate. Finally, the degree of downward wage flexibility has clearly an important role for the results. When, real wages are strictly downward rigid, $\kappa=0$, what matters for long-run unemployment is just the ratio between volatility and trend of productivity growth. With more flexibility downward, i.e. a positive $\kappa$, unemployment costs will be lower, for the same trend and volatility in productivity growth. In the limiting case of complete flexibility in real wages, $\kappa \rightarrow \infty$, long-run unemployment collapses to the constant $\bar{u}$ driven purely by monopoly distortions, as previously discussed.

Another important result of our model is that, in the long run, real wages are expected to grow at the same rate as the productivity trend, $g$. This can be seen easily seen by taking the time- 0 expectation of (6)

$$
E_{0}\left[u_{t}\right]=\bar{u}+\gamma\left(E_{0}\left[\ln w_{t}\right]-\ln A_{0}-g \cdot t-\bar{w}\right) .
$$

the process behave like a standard Brownian motion.

${ }^{11}$ See Cox and Miller (1990, pp. 223-225) for a detailed derivation. 
After dividing both sides of the above equations by $t$ and taking the limit, we get ${ }^{12}$

$$
\lim _{t \rightarrow \infty} \frac{E_{0}\left[u_{t}\right]}{t}=\gamma\left(\lim _{t \rightarrow \infty} \frac{E_{0}\left[\ln w_{t}\right]}{t}-g\right) .
$$

Using the result in $(7)$ that $E_{0}\left[u_{\infty}\right]$ converges to a finite number, then it follows that $\lim E_{0}\left[\ln w_{t} / t\right]=g$, where the limit is taken for $t \rightarrow \infty$. Intuitevely by looking at Figure (3), one should expect that periods of constant wages will be eventually followed by periods in which real wages catch up with productivity so that the expectation on where the real wage should be in the long run is aligned with the trend in productivity growth. This result contrasts with the models of Ball and Mankiw (2002) and Ball and Moffit (2002) where real wages do not catch with productivity growth in the long run.

It is worth noting that in our model, whereas the distribution of productivity growth is symmetric, that of real-wage growth is going to be skewed. Indeed, it is mainly the difference between the shape of the two distributions which translates into unemployment costs, through equation (6). This is important, as our model entails a long run effect of productivity on unemployment even when wages catch up with productivity in the long run, while with such catch up there would be no effect at all in models with symmetric wage rigidities.

\section{Evidence for the United States}

A key prediction of the theoretical model is that the variance of productivity growth has explanatory power, over the long run, for the mean of the unemployment rate over and above the role played by the mean of productivity growth. The Great Moderation and the recent Great Recession appear sensible candidates to evaluate the predictions of our theory. After 1984, the U.S. economy was characterized by lower macroeconomic volatility, which was associated with lower average unemployment despite flat productivity growth (see Figure 1). The opposite occurred in late 2000s: high volatility and unemployment, despite flat productivity. This section presents empirical evidence supporting this visual observation.

In order to retrieve estimates of the long-run mean of unemployment and productivity growth as well as the variance of productivity growth, we follow two strategies consistent with what presented in Figure 1. Under the first strategy, these long-run statistics are computed using averages and variances over 5-year rolling-windows. Under the second strategy, we estimate an empirical model with time-varying parameters and then focus

\footnotetext{
${ }^{12}$ For a formal proof, see Harrison and Reiman (1981).
} 
on the long-run statistics implied by the time-varying estimates. In particular, following the literature popularized by Cogley and Sargent (2005), Primiceri (2005), Canova and Gambetti (2009), and Galì and Gambetti (2009), we model the evolution of productivity growth, $g_{t}$, real wage growth, $\Delta w_{t}$, and the rate of unemployment, $u_{t}$, using a VAR with drifting coefficients and stochastic volatilities, which evolve as (driftless) random walks and geometric random walks respectively. The drifting coefficients enable us to construct a time-varying measure for the mean of the variables of interest. Both the drifting coefficients and the stochastic volatilities allow us to construct a time-varying measure of volatility. Details of the model specification, estimation method and the construction of time-varying means and variances from the estimates of the VAR are summarized in the Appendix.

The data were collected from the Fred database available at the Federal Reserve bank of St. Louis. Productivity is the non-farm business sector output per hour of all persons (acronym 'OPHNFB'), wage is the non-farm business sector real compensation per hour (acronym 'COMPRNFB'), and unemployment is the rate of civilian unemployment for persons with 16 years of age or older (acronym 'UNRATE'). ${ }^{13}$ We use seasonally adjusted quarterly data from 1949Q1 to 2010Q2 (where the first part of the sample is used as training sample in the VAR, as described below). We compute annual growth rates for productivity and real wage to smooth out the high frequency components of the data. Growth rates are approximated by log differences. Results are robust to using quarterly changes.

Under the VAR strategy, the coefficients priors are calibrated using a training sample of thirteen years, from 1949Q1-1961Q4. The results hereafter, are based on the estimation sample 1962Q1 to 2010Q2. The estimates of long run unemployment $\left(\tilde{u}_{t}\right)$, long run productivity $\left(\tilde{g}_{t}\right)$, and the variance of productivity $\left(\tilde{\sigma}_{t}^{2}\right)$ are obtained from the estimates of the time-varying VAR using Appendix equation (B.1) together with the formulas (B.9) and (B.10). These series are shown in Figure 1. Under the rolling-windows approach, the sample ends in 2008Q1 and the observation at a generic quarter refers to the 5 year (19 quarters) moving average centered at that quarter.

\footnotetext{
${ }^{13}$ To make our empirical results comparable with earlier contributions (see for instance Staiger, Stock and Watson, 2001), we measure productivity as the ratio of output to total hours in the non-farm business sector, $Y / L$. This measure is computed and released by the Bureau of Labour Statistics. In our model, productivity is defined as $Y / L^{\alpha}$ and the first difference of its logarithm is denoted by $g$. Note that assuming a standard labour to capital ratio of $2 / 3$ the correlation between $g$ and the first difference of the logarithm of $Y / L$ is 0.91 over our sample period. In Section 4, we present some robustness analysis using total factor productivity.
} 


\subsection{Fit of linear models}

This section presents some empirical evidence consistent with the main predictions of the model: the mean of unemployment depends negatively from the mean of productivity growth and positively from the variance of productivity growth. To verify these hypotheses, one needs to rely on regressions involving low-frequency trends. As such, the analysis below bears some similarities with the band spectral regression analysis pioneered by Engle (1974) and studied by a large body of subsequent research. An important take away from that literature is that low frequency band estimation does not pose a challenge for consistency but the estimates of the coefficient variance are biased because of serial correlation in the disturbances. As discussed by Engle (1974), if the filter has a rectangular window (as for instance when using a moving average) the bias in the standard error will be due only to a loss of degrees of freedom, coming from the fact that the inference is now based on $T / h$ (rather than $T$ ) observations where $h$ represents the size of the smoothing window in unit of times.

Unfortunately, it has proved hard in the literature to develop appropriate tools for reliable inference in this context. Engle (1974), for instance, suggests adjusting the standard errors by the reduced number of degrees of freedom. Alternatively, one may wish to employ very long lags in the formula provided by Newey and West (1987) to account for heteroskedasticity and auto-correlation in the error term. While these adjustments go some way towards addressing the disturbances serial correlation, they generally allow to generate suggesting rather than conclusive evidence. To enhance reliability of results, we adjust the standard error estimates using a window of 20 quarters. The reason for this choice is twofold. First, the rolling windows evidence is based on filtering out frequency above five years. Second, in the Appendix we show that, using the low frequency components extracted by the rolling windows or implied by the VAR, the estimates of the standard errors tend to flatten out (or even decrease) after a lag truncation of about 20 quarters in the Newey-West formula.

As for the empirical specification, a natural benchmark of comparison for assessing the role of productivity volatility in explaining low-frequency movements in unemployment is the linear regression employed in earlier contributions (see for instance Pissarides and Vallanti, 2007), which relates long-run unemployment to long-run productivity growth:

$$
\tilde{u}_{t}=a-b \cdot \tilde{g}_{t}+\varepsilon_{t}
$$

where $a$ and $b$ are parameters and $\varepsilon_{t}$ is a well-behaved stochastic disturbance. Using the rolling-window filter, we project long-run unemployment on long-run productivity growth 
as in equation (8):

$$
\tilde{u}_{t}=\underset{(0.004)}{0.08}-\underset{(0.142)}{0.86} \cdot \tilde{g}_{t}+\hat{\varepsilon}_{t}
$$

which results in a $R^{2}$ of 0.33 . The adjusted standard errors reported in parenthesis are based on the Newey-West formula with a lag truncation of 20 quarters. ${ }^{14}$ Repeating the estimation of equation (8) using the time-varying means implied by the estimates of the VAR, we obtain

$$
\tilde{u}_{t}=\underset{(0.004)}{0.10}-\underset{(0.196)}{2.25} \cdot \tilde{g}_{t}+\hat{\varepsilon}_{t}
$$

with an $R^{2}$ of the regression equal to 0.73 .

The estimates of these simple models show that there is a tight negative relationship between productivity growth and unemployment in the long-run. Under both regressions, the coefficient are significant. In particular, a $1 \%$ fall in long-run productivity growth corresponds to an increase in long-run unemployment of 0.86 percentage point using the rolling windows and 2.25 percentage points with the VAR estimates.

Figure 4 confronts long-run unemployment, depicted as a red line, with the fitted values from equation (9) and (10) respectively, depicted as blue dotted and dash lines, respectively. The linear model appears to do a good job in tracking qualitatively the movements in the unemployment rate. However, a closer inspection of the figure reveals that the linear model cannot adequately explain the decline in trend unemployment between 1984 and 1992, the rise since the late 1990s, and the developments since 2007.

The theoretical model of Section 2 suggests two departures from the linear specification (8). First, it highlights the relevance of the variance of productivity growth. Consistent with Figure 1, movements in the variance of productivity growth coincide with movements in long-run unemployment, especially during the periods where the mean of productivity growth does not have much explanatory power. Second, under the limiting case of downward real wage inflexibility, the model allows us to derive a nonlinear relationship between unemployment and productivity growth in closed form.

To appreciate the relative importance of these modifications, we proceed in two steps. First, within this section, we augment the linear specification in (8) with a variance term. Then, in next section, we estimate the relationship between unemployment and productivity growth nonlinearly.

Remaining within a linear framework, we estimate the following specification which

\footnotetext{
${ }^{14}$ Using a $T / 20$ adjustment for computing the degrees of freedom of an otherwise conventional standard error produces estimates which are on average $50 \%$ to $80 \%$ larger than the standard errors based on the Newey-West correction.
} 

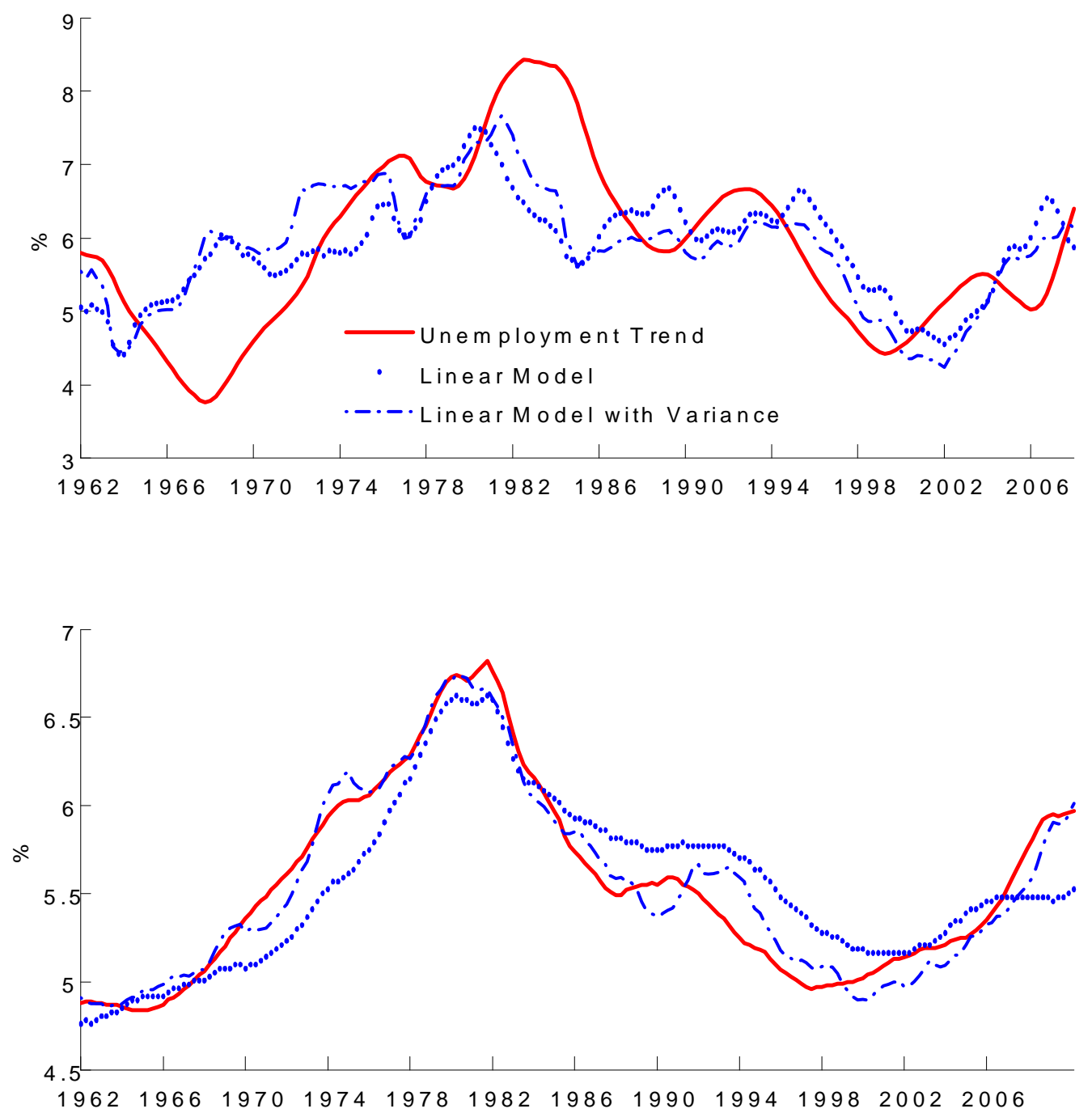

Figure 4: Trend in the unemployment rate and fitted values for the Linear Model, (8), and the Linear Model with Variance, (11). The top chart displays the fitted values, (9) and (12), using 5-yr rolling-window-average data for unemployment trend, productivitygrowth trend and its variance. The bottom chart displays the fitted values, (10) and (13), using data from the estimates of the time-varying VAR for unemployment trend, productivity-growth trend and its variance. Percent rates. 
features both the mean and the variance of productivity growth:

$$
\tilde{u}_{t}=a-b \cdot \tilde{g}_{t}+c \cdot \tilde{\sigma}_{t}^{2}+\varepsilon_{t} .
$$

Using the data retrieved from 5-year rolling-window averages, the following is the result of the estimation:

$$
\tilde{u}_{t}=\underset{(0.003)}{0.07}-\underset{(0.134)}{0.81} \cdot \tilde{g}_{t}+\underset{(12.52)}{26.88} \cdot \tilde{\sigma}_{t}^{2}+\hat{\varepsilon}_{t}
$$

where the variance term is significant and the $R^{2}$ of the regression now rises to 0.44 . Repeating the same estimation using the long-run statistics obtained from the VAR estimates, we get

$$
\tilde{u}_{t}=\underset{(0.003)}{0.08}-\underset{(0.100)}{1.68} \cdot \tilde{g}_{t}+\underset{(4.853)}{50.83} \cdot \tilde{\sigma}_{t}^{2}+\hat{\varepsilon}_{t}
$$

where the $R^{2}$ is again higher at 0.95 .

Both regressions display an increase in the $R^{2}$ relative to the estimates based on a linear specification in long-run productivity growth only. Not surprisingly, as also visible in Figure 4, the fitted values from equations (12) and (13) track unemployment trend better than the respective linear models (9) and (10). The improvement is particularly evident for the VAR, where the introduction of the variance terms allows the model to better account for the decline in long-run unemployment of the 1980 and the rise of the late 2000s, compared to the specification with just productivity. Overall, the coefficient on the productivity mean is somewhat lower than in the linear specification.

The effect of the variance is also economically significant: under the first specification an increase of one standard deviation (0.00014) would imply a rise in long-run unemployment of about 0.35 percent, while under the second specification an increase of one standard deviation (0.00005) would imply an increase in long-run unemployment of about 0.25 percent. In particular, the VAR-based estimates in Figure 1 reveal that the variance of productivity growth declined from 0.0003 to about 0.00025 during the second half of the 1980s when long-run unemployment fell from about $6 \%$ to $5.5 \%$. In light of the estimated coefficients in (13), this implies that the decline in the variance of productivity growth can account for about $50 \%$ of the fall in long-run unemployment during this episode. Between 2000 and 2009, the variance of productivity growth has increased from 0.00024 to 0.0004 against the backdrop of a rise in long-run unemployment from $5 \%$ to $6 \%$. These numbers imply a $80 \%$ contribution of the variance of productivity growth to long-run unemployment during the 2000s. 


\subsection{Fit of the non-linear model}

We now turn to the nonlinear specification explicitly suggested by our model:

$$
\tilde{u}_{t}=\bar{u}+\frac{1}{2} \gamma \cdot\left(\frac{\tilde{\sigma}_{t}^{2}}{\tilde{g}_{t}+\kappa}\right)+\varepsilon_{t} .
$$

Using the 5-yr rolling-window estimates, we obtain:

$$
\tilde{u}_{t}=\underset{(0.003)}{0.049}+\frac{1}{2} 1.708 \cdot\left(\frac{\tilde{\sigma}_{t}^{2}}{\tilde{g}_{t}+\underset{(0.009)}{0.004}}\right)+\varepsilon_{t} .
$$

with an $R^{2}$ of 0.38 . Repeating the same regression using the VAR estimates, we find:

$$
\tilde{u}_{t}=\underset{(0.003)}{0.038}+\frac{1}{2} 1.554 \cdot\left(\frac{\tilde{\sigma}_{t}^{2}}{\tilde{g}_{t}-\underset{(0.002)}{0.007)}}\right)+\varepsilon_{t} .
$$

displaying an $R^{2}$ of 0.93 .

The fitted values associated with the non-linear models are presented in Figure 5. This specification tends to track long-run unemployment well and seems to outperform the linear specification of Figure 4 which is based on long-run productivity growth only. In particular, the nonlinear model appears to capture well the fall in long-run unemployment during the 1984-1992 period and its increase during the late 2000s.

The above results bear interesting implications in terms of the primitive parameters of the model. The flexible-wage unemployment rate, $\bar{u}$, is precisely estimated, under both specifications, in the range of $4 \%$ to $5 \%$. Downward real wage rigidities play a significant role. The threshold for such rigidities $\kappa$ is estimated at values around 0, i.e. close to plain downward wage rigidities. Using the 5-year rolling-windows, a positive (although statistically indistinguishable from zero) $\kappa$ is estimated at around $0.4 \%$ on an annul basis, meaning that real wages can fall at most $0.4 \%$ when evaluated over a year horizon, which is a number consistent with the degree of downward wage rigidity shown at the aggregate level for the U.S. in Figure 2. Under the time series built using the VAR estimates, $\kappa$ is negative and around $0.7 \%$ on annul basis meaning that the best fit of the model requires wage growth to exceed at least $0.7 \%$ from year to year. Notice that if we constrained $\kappa$ to be non-negative, then $\kappa$ would turn out to be zero, $\gamma$ would be estimated at 2.94 , with a standard error of 0.3188 , and $\bar{u}$ would be estimated at 0.034 , with a standard error of 0.008 .

The estimate of $\gamma$ can be used to make some inference on other primitive parameters of 

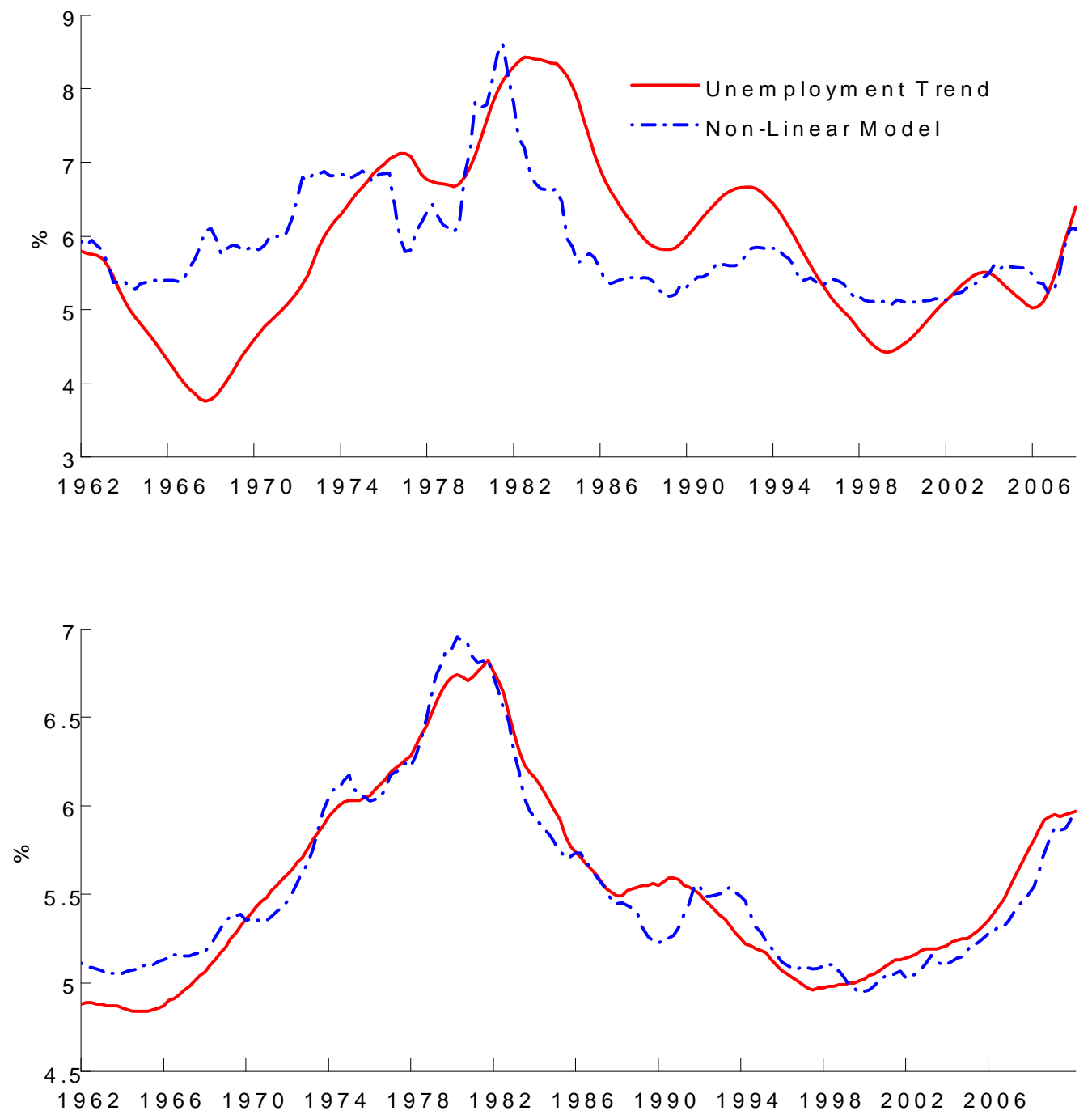

Figure 5: Trend in the unemployment rate and fitted values for the Non-Linear Model, (14). The top chart displays the fitted value, (15), using 5-yr rolling-window-average data for unemployment trend, productivity-growth trend and its variance. The bottom chart displays the fitted values, (16), using data from the estimates of the time-varying VAR for unemployment trend, productivity-growth trend and its variance. Percent rates. 
the model: the exponent of labor in the production function, $\alpha$, and the Frisch elasticity of labor supply, $\eta$. A value for $\gamma$ equal to 1.71 as in (15) is consistent with low values for the Frisch elasticity and for $\alpha$ (not larger than 0.4); the estimate in (16) implies a slightly smaller upper bound on $\alpha$. However, when we restrict $\kappa$ to be non-negative, then a value of $\gamma$ equal to 2.94 can be consistent with values of $\alpha$ up to 0.66 while the estimated Frisch elasticity of labor supply would still be small.

In summary, versions of the theoretical model that feature asymmetries in real rigidities appear to account for the low-frequency movements in the U.S. unemployment rate better than a model with symmetric real rigidity.

\section{Sensitivity analysis}

In this part of the paper, we assess the robustness of the empirical regularities documented above along three dimensions: sub-sample stability, using a measure of total factor productivity (in place of labour productivity) and controlling for demographics. For simplicity and comparability with existing literature, the linear specification is chosen as a reference. To preview the results, none of these modifications appears to overturn our earlier findings of a negative correlation between unemployment and productivity growth trends and a positive correlation between the unemployment trend and the volatility of productivity growth.

\subsection{Sub-samples}

As discussed in the previous section, the focus on low-frequency components implies that our inference is in fact based on fewer observations than the actual full-sample. To assess the extent to which our results may be driven by specific historical episodes, we perform here a sub-sample analysis splitting the sample around 1983Q4, a cut-off for the beginning of the great moderation consistent with the dating estimated by Kim and Nelson (1999) and Stock and Watson (2002). For this exercise, we report results based on the specification (11) but the estimates are robust to using either (8) or (14).

The findings for the sub-sample 1962Q1-1983Q4 based on the five years rolling and 
the VAR estimates are respectively: $:^{15}$

$$
\begin{array}{ll}
\tilde{u}_{t}=\underset{(0.006)}{0.07}-\underset{(0.245)}{1.02} \cdot \tilde{g}_{t}+\underset{(13.62)}{32.22} \cdot \tilde{\sigma}_{t}^{2}+\hat{\varepsilon}_{t}, \quad R^{2}=0.53 \\
\tilde{u}_{t}=\underset{(0.003)}{0.08}-\underset{(0.069)}{1.87} \cdot \tilde{g}_{t}+\underset{(5.586)}{41.89} \cdot \tilde{\sigma}_{t}^{2}+\hat{\varepsilon}_{t}, \quad R^{2}=0.98
\end{array}
$$

whereas the estimates associated with the post-1983 period are respectively:

$$
\begin{array}{ll}
\tilde{u}_{t}=\underset{(0.003)}{0.06}-\underset{(0.089)}{0.53} \cdot \tilde{g}_{t}+\underset{(16.02)}{78.72} \cdot \tilde{\sigma}_{t}^{2}+\hat{\varepsilon}_{t}, \quad R^{2}=0.65 \\
\tilde{u}_{t}=\underset{(0.006)}{0.07}-\underset{(0.221)}{1.24} \cdot \tilde{g}_{t}+\underset{(7.180)}{54.78} \cdot \tilde{\sigma}_{t}^{2}+\hat{\varepsilon}_{t}, & R^{2}=0.83
\end{array}
$$

In summary, we conclude that the negative correlation between unemployment and productivity growth trends as well as the positive relationship between long-run unemployment and the volatility of productivity growth appear stable across a sample split around the onset of the great moderation.

\subsection{Total factor productivity}

While labour productivity is likely to be lesser prone to measurement errors, Total Factor Productivity (TFP) is probably closer to the theoretical concept in the model of Section 2. Accordingly, in this section we explore the extent to which our results are robust to replacing labour productivity growth with TFP growth in the estimates of equation (11). More specifically, we employ the quarterly measure of TFP constructed by Fernald (2012) for the United States to compute the low-frequency component and the volatility of productivity growth using either 5 year rolling windows or a time-varying VAR that otherwise would be identical to the one used for labour productivity growth.

The estimates based on the rolling window filter are as follows:

$$
\tilde{u}_{t}=\underset{(0.003)}{0.06}-\underset{(0.149)}{0.59} \cdot \tilde{g}_{t}+\underset{(7.74)}{17.17} \cdot \tilde{\sigma}_{t}^{2}+\hat{\varepsilon}_{t}
$$

with $R^{2}=0.37$, whereas the regression based on the estimates from the time-varying VAR reads:

$$
\tilde{u}_{t}=\underset{(0.004)}{0.06}-\underset{(0.162)}{1.22} \cdot \tilde{g}_{t}+\underset{(6.61)}{40.13} \cdot \tilde{\sigma}_{t}^{2}+\hat{\varepsilon}_{t}
$$

\footnotetext{
${ }^{15}$ In keeping with the previous analysis, standard errors correct for heteroskedasticity and autocorrelation using the Newey-West formula and 20 quarters truncation. The results below are robust to using the $T / 20$ degree of freedom adjustment in the computation of otherwise conventional standard errors.
} 
with $R^{2}=0.82$. Under both specifications, the mean and variance of productivity growth still appear as significant determinants of long-run unemployment, with estimates that are not statistically different from those obtained using labour productivity growth.

\subsection{Controlling for demographics}

An important strand of the literature has convincingly argued that changes in the demographic composition of the labour force affects the low-frequency movements in unemployment (Shimer, 1998), the low-frequency movements in productivity (Francis and Ramey, 2009) and the variance of real output growth (Jaimovich and Siu, 2009).

In this section, we assess the robustness of the estimates from the linear specification to controlling for demographics. To this end, we construct time series for the share of workers in the labor force with age (i) between 16 and 21 (as in Francis and Ramey, 2009), (ii) between 16 and 34 (as in Shimer, 1998), and (i) the sum of the shares of workers in the 16-29 and the 60-64 windows of age (as in Jaimovich and Siu, 2009). We then use each of these three demographic indicators as additional controls in equations (8) and (11), one at the time. In addition, in a fourth regression, we construct a different left-hand-side variable to proxy for what Shimer (1998) refers to as a measure of genuine unemployment which is not affected by demographics; this is done by running a regression of the unemployment rate on a constant and the unemployment rate of workers in prime age (defined as those between 35 and 64 years). ${ }^{16}$ Then, we use the 5-year rolling-window averages of the fitted values from this regression in place of the 5-year rolling-window unemployment rate. As for the VAR, we replace the unemployment rate with genuine unemployment and use it together with productivity growth and real wages to extract the low-frequency components and variances of the variables of interest in a newly estimated time-varying VAR which is otherwise all alike the one used in the Section $3 .{ }^{17}$

The results of these sensitivity analyses are reported in Tables 1 and 2 for the 5-year rolling-windows and for the time-varying VAR estimates, respectively. The tables present estimates for the linear model using the trend of productivity growth and the measures of labor force share in columns 1 to 3 , as in equation (8), and then adding the variance of productivity growth in columns 5 to 7 , as in equation (11) The estimates for the specifications using Shimer's measure of genuine unemployment are displayed in columns 4 and 8 , without and with the variance of productivity growth respectively.

\footnotetext{
${ }^{16}$ The estimated coefficients (standard errors) of this regression are: 0.0075 (0.0014) for the intercept and $1.2716(0.0340)$ for the slope. $R^{2}=0.851$. Sample: 1948Q1:2010Q2.

${ }^{17}$ The labor force series were collected from the Bureau of Labor Statistics using data gathered in the Current Population Survey. These data can also be used to compute the unemployment rate for prime-age workers. The series used in this section are reported in the Appendix.
} 
Two main results emerge from Tables 1 and 2. First, controlling for demographics does not seem to overturn our finding of a role played by both the long-run mean and the variance of productivity growth to explain low-frequency movements in unemployment. In particular, the estimated coefficient on $\tilde{\sigma}_{t}^{2}$ in columns 5 to 8 is positive and large, at values that are not inconsistent with the estimates in (9) and (10). Similar results are obtained for the estimated coefficient on $\tilde{g}_{t}$, although its effect is sometimes smaller than the estimated counterpart based on specifications without demographics. 


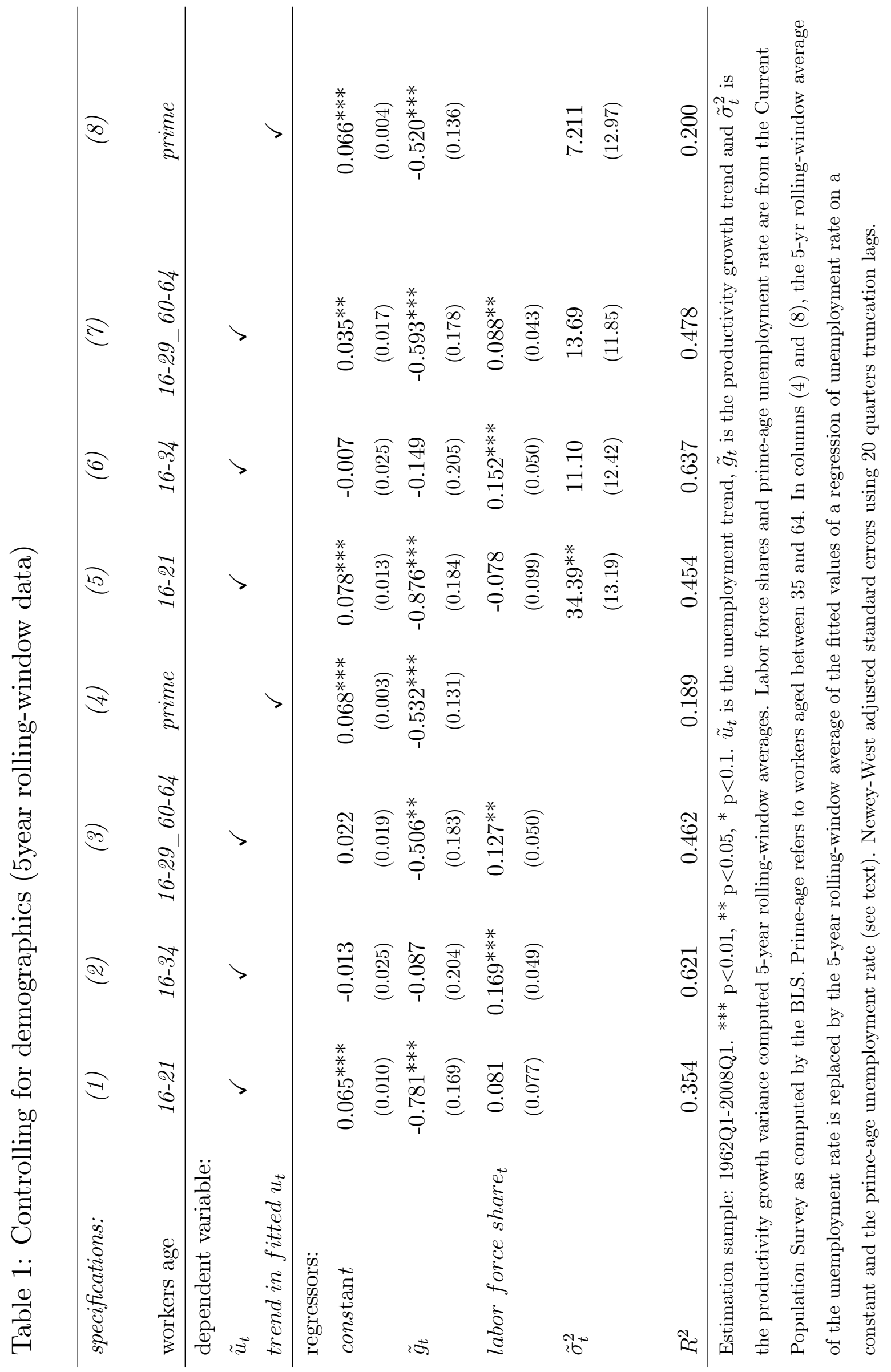




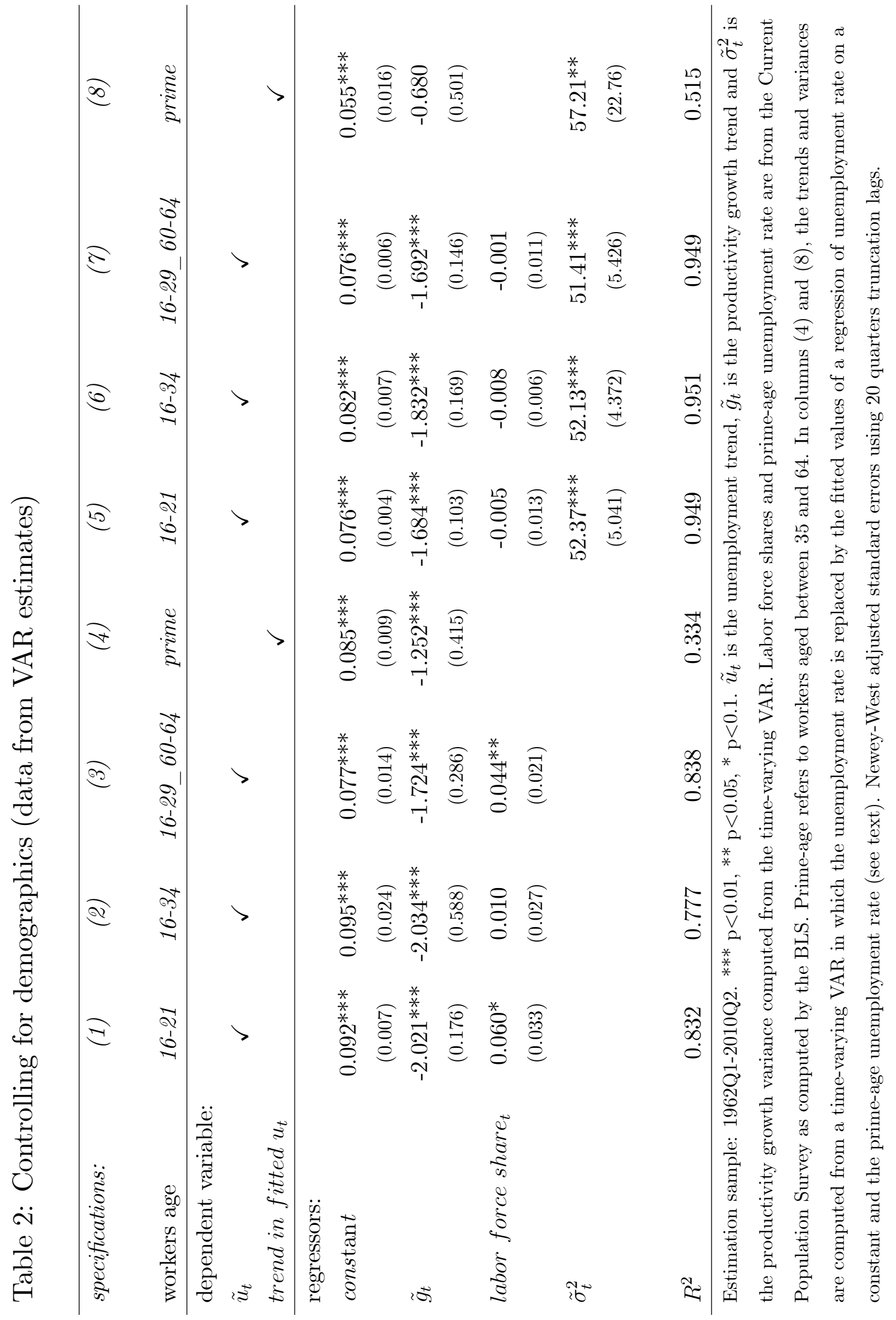


Second, in line with Shimer (1998), Francis and Ramey (2009) and Jaimovich and Siu (2009), the composition of the labor force tends to have a non-negligible influence on the low-frequency movements in unemployment, although its robustness and significance appear muted once the variance of productivity growth is added as additional regressor in the columns 5 to 7 of both tables.

In summary, the long-run mean and the variance of productivity growth appear to play some role as drivers of U.S. long-run unemployment, over and above the role played by changes in the demographic composition of the labor force.

\section{Conclusions}

Productivity growth and unemployment appear to be negatively related in the long-run, in a way that depends positively on the variance of productivity growth. A simple model of the labor market based on downward real wage rigidities is shown to generate predictions that are consistent with this empirical finding.

Our evidence on U.S. data reveals that higher volatility of productivity growth and lower levels of long-run productivity growth tend to be associated with higher levels of long-run unemployment. In particular, the results suggest that movements in the variance of productivity growth may account for about $50 \%$ of the fall in long-run unemployment during the second half of the 1980s and for about $80 \%$ of the increase in long run unemployment during the 2000s. 


\section{References}

[1] Abel, A. B. and J. C. Eberly, 1994, "A Unified Model of Investment Under Uncertainty," The American Economic Review, Vol. 84, No. 5, pp. 1369-1384.

[2] Aghion, Philippe and Peter Howitt, 1994 "Growth and Unemployment", Review of Economic Studies, vol. 61, pp. 477-494.

[3] Babecký, Jan, Philip Du Caju, Theodora Kosma, Martina Lawless, Julián Messina, Tairi Rõõm, 2010, "Downward Nominal and Real Wage Rigidity: Survey Evidence from European Firms", The Scandinavian Journal of Economics, Vol. 112, Issue 4, pp. 884-910.

[4] Baker, S., N. Bloom and S. Davis, 2012, "Measuring Economic Policy Uncertainty", mimeo, Stanford University and Chicago Booth.

[5] Ball, Laurence and Greg Mankiw, 2002, "The Nairu in Theory and Practice," Journal of Economic Perspectives, vol. 16(4) 115-136.

[6] Ball, Lawrence and Robert Moffitt, 2002, "Productivity Growth and the Phillips Curve," In The Roaring Nineties: Can Full Employment be Sustained?, edited by A. B. Krueger and R. Solow. (New York: Russell Sage Foundation).

[7] Barnichon, Regis, 2010, "Productivity and Unemployment over the Business Cycle," Journal of Monetary Economics 57, pp. 1013-1015.

[8] Barwell Richard D. and Mark E. Schweitzer, 2007, "The Incidence of Nominal and Real Wage Rigidities in Great Britain: 1978-98", The Economic Journal, Vol. 117 issue 524, pp: F553-F569.

[9] Bauer, T., H. Bonin, L. Goette, and U. Sunde, 2007, "Real and Nominal Wage Rigidities and The Rate of Inflation: Evidence from West German Micro Data", The Economic Journal, Vol. 117, issue 524, pp: F508-F529.

[10] Benigno, Pierpaolo, Luca A. Ricci, Paolo Surico, 2010, "Unemployment and Productivity in the Long Run: The Role of Macroeconomic Volatility," NBER Working Paper No. 16374.

[11] Blanchard Olivier and Jordi Galí, 2010, "Labor Markets and Monetary Policy: A New Keynesian Model with Unemployment," American Economic Journal: Macroeconomics, vol. 2, pp.1-30. 
[12] Blanchard, Olivier, Rovert Solow and B. A.Wilson, 1995, "Productivity and Unemployment," Massachusetts Institute of Technology. Mimeo.

[13] Blanchard, Olivier and Justin Wolfers, 2000, "The Role of Shocks and Institutions in the Rise of European Unemployment: The Aggregate Evidence", Economic Journal, $110,1-33$.

[14] Bloom, Nick, 2009, "The Impact of Uncertainty Shocks", Econometrica, 77, 623-685.

[15] Bruno, M. and J. D. Sachs, 1985, Economics of Worldwide Stagflation. (Cambridge, Massachusetts, Harvard University Press).

[16] Canova, Fabio and Luca Gambetti, 2009, "Structural Changes in the US Economy: Is There a Role for Monetary Policy?," Journal of Economic Dynamics and Control 33, pp. 477-490.

[17] Christofides, L.N. and D. Li, 2005, "Nominal and Real Wage Rigidity in a Friction Model", Economics Letters, Vol. 87(2), 235-241.

[18] Christofides, Louis N. and P. Nearchou, 2010, "Patterns of Nominal and Real Wage Rigidity", Research in Labor Economics, Vol. 30, pp. 301-337.

[19] Cogley, Tim, and Tom J. Sargent, 2005, "Drift and Volatilities: Monetary Policies and Outcomes in the Post WWII US," Review of Economic Dynamics 8, pp. 262-302.

[20] Cox, D.R. and H.D. Miller, 1990, The Theory of Stochastic Processes, Chapman and Hall.

[21] Devicienti Francesco, Agata Maida, and Paolo Sestito, 2007, "Downward Wage Rigidity in Italy: Micro-Based Measures and Implications", The Economic Journal, Vol. 117 issue 524, pp: F530-F552.

[22] Dickens, W. T., Goette, L. F., Groshen, E. L., Holden, S., Messina, J., Schweitzer, M. E., Turunen, J. and M. E. Ward-Warmedinger, 2008, "Downward Real and Nominal Rigidity: Micro Evidence from the International Wage Flexibility Project", unpublished manuscript, Eurosystem Wage Dynamics Network.

[23] Du Caju, P., Fuss, C., and L. Wintr, 2009, "Understanding Sectoral Differences in Downward Real Wage Rigidity: Workforce Composition, Institutions, Technology and Competition," ECB WP 1006. 
[24] Dunlop, J.T., 1944, Wage Determination under Trade Unionism (MacMillan, New York).

[25] Elsby, M. W. L., 2009, "Evaluating The Economic Significance of Downward Nominal Wage Rigidity," Journal of Monetary Economics, Vol. 56, Issue 2, pp. 154-169.

[26] Engle, Robert, 1974, "Band Spectrum Regression", International Economic Review 15, pp. 1-11.

[27] Fabiani Silvia, Claudia Kwapil, Tairi Rõõm, 2010, "Wage Rigidities and Labor Market Adjustment in Europe", Journal of the European Economic Association, Vol. 8, Issue 2-3, pages 497-505.

[28] Fagan Gabriel and Julian Messina, 2009, "Downward Wage Rigidity and Optimal Steady-State Inflation," ECB WP 1048.

[29] Fernald, John, 2012, "A Quarterly, Utilization-Adjusted Series on Total Factor Productivity", Federal Reserve Bank of San Francisco Working paper No. 2012-19.

[30] Fernandez-Villaverede, Jesus, K. Kuester, Pablo Guerron and Juan Rubio-Ramirez, 2011, "Fiscal Volatility Shocks and Economic Activity," NBER WP 17317.

[31] Francis, N. and V.A. Ramey, 2009, "Measures of per Capita Hours and Their Implications for the Technology-Hours Debate," Journal of Money, Credit and Banking, vol. 41, pp. 1071-1097.

[32] Galì, Jordi, and Luca Gambetti, 2009, "On the Sources of the Great Moderation," American Economic Journal: Macroeconomics 1, pp. 26-57.

[33] Galì, Jordi, 2011, "The Return of the Wage Phillips Curve," Journal of the European Economic Association 9 (3), pp. 436-461.

[34] Gertler, Mark and Antonella Trigari, 2009, "Unemployment Fluctuations with Staggered Nash Wage Bargaining," Journal of Political Economy 117, pp. 38-86.

[35] Hairault Jean-Olivier, Francois Langot, Sophie Osotimehin, 2010, "Matching Frictions, Unemployment Dynamics and the Cost of Business Cycles", Review of Economic Dynamics, Vol. 13, Issue 4, pp.759-779.

[36] Hall, Robert E., 2005, "Employment Fluctuations with Equilibrium Wage Stickiness," American Economic Review 95, pp. 50-65. 
[37] Harrison, M. J. and M. I. Reiman, 1981, "On the Distribution of Multi-dimensional Rełected Brownian Motion," SIAM Journal of Applied Mathematics, Vol. 41, No. 2, pp. 345-361.

[38] Holden, S. and F. Wulfsberg, 2009, "How Strong is the Macroeconomic Case for Downward Real Wage Rigidity?," Journal of Monetary Economics, vol. 56, pp.60516.

[39] Jaimovich, N. and H.E. Siu, 2009, "The Young, the Old, and the Restless: Demographics and Business Cycle Volatility," American Economic Review, vol. 99, pp. $804-26$.

[40] Kim, C.J., and C.R. Nelson, 1999, "Has the U.S. economy become more stable? A Bayesian approach based on a Markov-switching model of the business cycle", The Review of Economics and Statistics 81, pp. 608-616.

[41] Kim, C.J. and C.R. Nelson, 2000, "State-Space Models with Regime Switching", the Mit Press.

[42] Kim, J. and F. J. Ruge-Murcia, 2009, "How Much Inflation is Necessary to Grease the Wheels?" Journal of Monetary Economics, 56(3): 365-77.

[43] Krause, M. U. and T.A. Lubik, 2007, "The (Iir)relevance of Real Wage Rigidity in The New Keynesian Model with Search Frictions," Journal of Monetary Economics, Vol. 54, Issue 3, pp. 706-727.

[44] Messina, Julián, Cláudia Filipa Duarte, Mario Izquierdo, Philip DU Caju, Niels Lynggård Hansen, 2010, "The Incidence of Nominal and Real Wage Rigidity: An Individual-Based Sectoral Approach", Journal of the European Economic Association, Vol. 8, Issue 2-3, pages 487-496.

[45] Mortensen, Dale T. and Chris A. Pissarides, 1998, "Technological Progress, Job Creation, and Job Destruction," Review of Economic Dynamics, Vol. 1, Issue 4, pp. 733-753.

[46] Newey, Whitney K. and Kenneth West, 1987 "A Simple, Positive Semi-definite, Heteroskedasticity and Autocorrelation Consistent Covariance Matrix", Econometrica 55, pp. 703-708.

[47] Phelps Edmund S., 1994, Structural Slumps, The Modern Equilibrium Theory of Unemployment, Interest and Assets. (Cambridge MA: Harvard University Press). 
[48] Pissarides, Chris A., 2000, Equilibrium Unemployment Theory. Cambridge, Mass: MIT Press.

[49] Pissarides, Chris A., 2009, "The Unemployment Volatility Puzzle: Is Wage Stickiness the Answer?," Econometrica, 77: 1339-1369.

[50] Pissarides, Chris and Giovanna Vallanti, 2007, "The Impact of TFP Growth on Steady-State Unemployment," International Economic Review, vol. 48 Issue 2, Pages 607-640.

[51] Primiceri, Giorgio, 2005, "Time-Varying Vector Autoregressions and Monetary Policy," Review of Economic Studies, 72, pp. 821-852.

[52] Rotemberg, Julio J., 1982, "Monopolistic Price Adjustment and Aggregate Output," Review of Economic Studies, Vol. 49, No. 4, pp. 517-531.

[53] Shimer, Robert, 1998, "Why is the U.S. Unemployment Rate so Much Lower?," NBER Macroeconomics Annual, vol. 13, pp. 11-74.

[54] Shimer, Robert, 2005, "The Cyclical Behavior of Equilibrium Unemployment and Vacancies," American Economic Review, 95(1), pp. 25-49.

[55] Shimer, Robert, 2010, "Wage Rigidities and Jobless Recoveries", mimeo.

[56] Staiger Douglas, Stock James and Mark Watson, 2001, "Prices, Wages and the U.S. NAIRU in the 1990s", Ch. 1 in The Roaring Nineties, A. Krueger and R. Solow (eds.), Russell Sage Foundation/The Century Fund: New York, pp. 3 - 60.

[57] Stock, James, and Mark Watson, 2002, "Has the business cycle changed and why?" in Gertler, M., and K.S. Rogoff (eds.) NBER Macroeconomics Annual, MIT Press, pp. 159-218. 


\section{ALL APPENDICES ARE NOT INTENDED FOR PUB- LICATION}

\section{A The data}
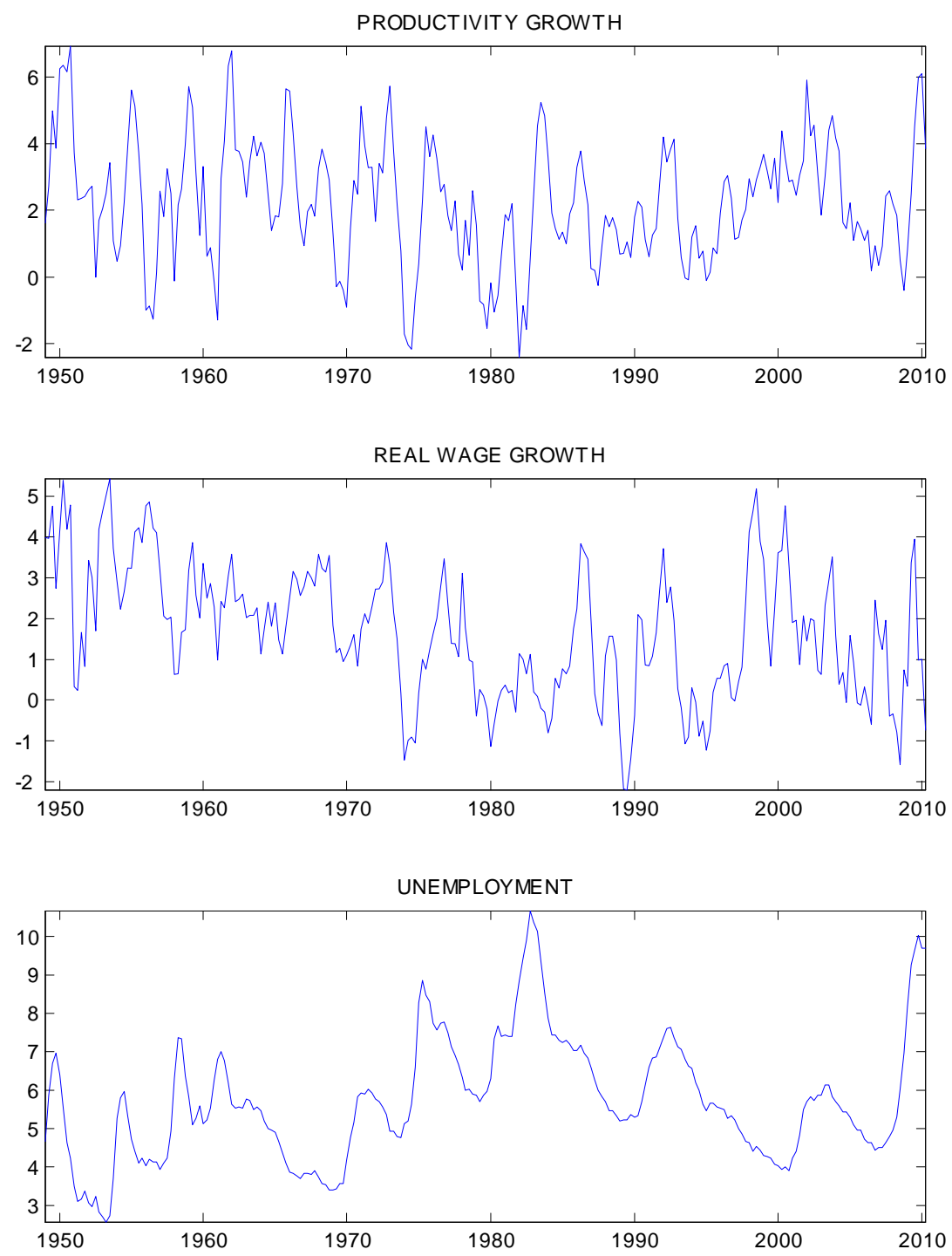

Figure 6: Productivity growth, unemployment and real wage growth, quarterly data on sample 1949Q1:2010Q2. All data are in percent. Productivity growth and real wage growth at annual rates. 

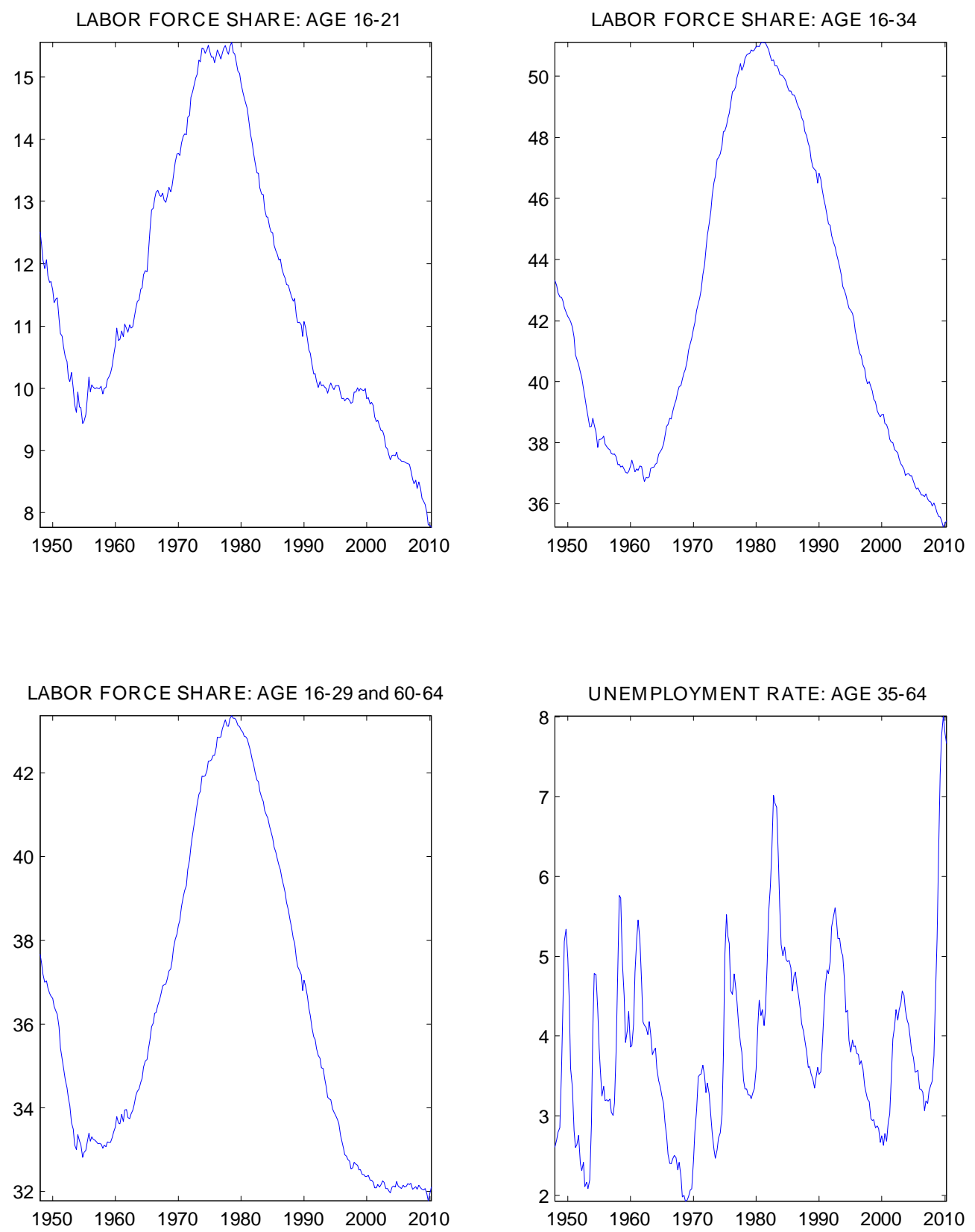

Figure 7: Labor force shares for workers with age between 16 and 21, between 16 and 34, between 16 and 29 plus between 60 and 64, unemployment rate for workers with age between 35 and 64, quarterly data on sample 1949Q1:2010Q2. Percent rates. 


\section{B A time-varying VAR with stochastic volatility}

The statistical model is a $\operatorname{VAR}(p)$ of the following form:

$$
Y_{t}=B_{0, t}+B_{1, t} Y_{t-1}+\ldots+B_{p, t} Y_{t-p}+\epsilon_{t} \equiv X_{t}^{\prime} \theta_{t}+\epsilon_{t}
$$

where $X_{t}^{\prime}$ collects the first $p$ lags of $Y_{t}, \theta_{t}$ is a matrix of time-varying parameters, $\epsilon_{t}$ are reduced-form errors, $Y_{t}$ is defined as $Y_{t} \equiv\left[g_{t}, \Delta w_{t}, u_{t}\right]^{\prime}$, and $p$ is set equal to 2. We stack the time-varying VAR parameters in the vector $\theta_{t}$, which is assumed to evolve as:

$$
p\left(\theta_{t} \mid \theta_{t-1}, Q\right)=I\left(\theta_{t}\right) f\left(\theta_{t} \mid \theta_{t-1}, Q\right)
$$

where $I\left(\theta_{t}\right)$ is an indicator function that takes a value of 0 when the roots of the associated VAR polynomial are inside the unit circle and is equal to 1 otherwise. $f\left(\theta_{t} \mid \theta_{t-1}, Q\right)$ is given by

$$
\theta_{t}=\theta_{t-1}+\eta_{t}
$$

with $\eta_{t} \sim N(0, Q)$. The VAR reduced-form innovations in (B.1) are postulated to be zeromean normally distributed, with time-varying covariance matrix $\Omega_{t}$ which is factored as

$$
\operatorname{Var}\left(\epsilon_{t}\right) \equiv \Omega_{t}=A_{t}^{-1} H_{t}\left(A_{t}^{-1}\right)^{\prime}
$$

The time-varying matrices $H_{t}$ and $A_{t}$ are defined as:

$$
H_{t} \equiv\left[\begin{array}{ccc}
h_{1, t} & 0 & 0 \\
0 & h_{2, t} & 0 \\
0 & 0 & h_{3, t}
\end{array}\right] \quad A_{t} \equiv\left[\begin{array}{ccc}
1 & 0 & 0 \\
\alpha_{21, t} & 1 & 0 \\
\alpha_{31, t} & \alpha_{32, t} & 1
\end{array}\right]
$$

with the elements $h_{i, t}$ evolving as geometric random walks:

$$
\ln h_{i, t}=\ln h_{i, t-1}+\nu_{i, t}
$$

Following Primiceri (2005), we postulate:

$$
\alpha_{t}=\alpha_{t-1}+\tau_{t}
$$


where $\alpha_{t} \equiv\left[\alpha_{21, t}, \alpha_{31, t}, \alpha_{32, t}\right]^{\prime}$, and assume that the vector $\left[\varepsilon_{t}^{\prime}, \eta_{t}^{\prime}, \tau_{t}^{\prime}, \nu_{t}^{\prime}\right]^{\prime}$ is distributed as

$$
\left[\begin{array}{c}
\varepsilon_{t} \\
\eta_{t} \\
\tau_{t} \\
\nu_{t}
\end{array}\right] \sim N(0, V), \text { with } V=\left[\begin{array}{cccc}
I_{4} & 0 & 0 & 0 \\
0 & Q & 0 & 0 \\
0 & 0 & S & 0 \\
0 & 0 & 0 & Z
\end{array}\right] \text { and } Z=\left[\begin{array}{ccc}
\sigma_{1}^{2} & 0 & 0 \\
0 & \sigma_{2}^{2} & 0 \\
0 & 0 & \sigma_{3}^{2}
\end{array}\right]
$$

where $\varepsilon_{t}$ is such that $\epsilon_{t} \equiv A_{t}^{-1} H_{t}^{\frac{1}{2}} \varepsilon_{t}$.

The time-series for long-run unemployment and long-run productivity growth are computed as local-to-date $t$ approximations to the mean of the endogenous variables of the VAR, evaluated at the posterior mean $E\left(\theta_{t \mid T}\right)$. Let us rewrite equation (B.1) in companion form:

$$
z_{t}=C_{t \mid T}+D_{t \mid T} z_{t-1}+\varsigma_{t}
$$

where $z_{t}$ contains current and lagged values of $Y_{t}, C_{t \mid T}$ is the vector of intercepts, $D_{t \mid T}$ is the vector of stacked time-varying parameters and $\varsigma_{t}$ is a conformable vector containing $\epsilon_{t}$ and zeros. Following Cogley and Sargent (2005), the long-run mean for the vector $z_{t}$ can then be computed as:

$$
\tilde{z}_{t}=\left(I-D_{t \mid T}\right)^{-1} C_{t \mid T}
$$

where, given the order of the variables in the VAR, the first and third elements of $\tilde{z}_{t}$ correspond to the mean of productivity growth, $\tilde{g}_{t}$, and the mean of unemployment, $\tilde{u}_{t}$, at time $t$.

The time-series for the unconditional variance of the variables in the VAR can be estimated using the integral of the spectral density over all frequencies, $\int_{\varpi} f_{t \mid T}(\omega)$, where $f_{t \mid T}$ is defined as:

$$
f_{t \mid T}(\omega)=\left(I-D_{t \mid T} e^{-i \omega}\right)^{-1} \frac{\Omega_{t \mid T}}{2 \pi}\left[\left(I-D_{t \mid T} e^{-i \omega}\right)^{-1}\right]^{\prime}
$$

The element $(1,1)$ of the matrix $f_{t \mid T}(\omega)$ represents the unconditional variance of productivity growth, $\tilde{\sigma}_{t}^{2}$, at time $t$.

The model (B.1)-(B.8) is estimated using Bayesian methods (see Kim and Nelson (2000)). Full descriptions of the algorithm, including the Markov-Chain Monte Carlo (MCMC) used to simulate the posterior distribution of the hyperparameters and the states conditional on the data, are provided in a number of papers (see, for instance, Cogley and Sargent, 2005, Primiceri, 2005, and Canova and Gambetti, 2009) and will not be repeated here.

Even though one cannot characterize analytically the joint posterior distribution of the model parameters, it is possible to construct a Markov chain whose invariant distribution 
is the posterior. The MCMC procedure draws from the marginal density of a set of random variables $j$, conditional on some realizations for another set of random variables $i$, and then drawing from the marginal distribution of $i$ conditional on the realizations of $j$ in the previous step. Under some assumption, the chain converge to an invariant density that equals the desired posterior density.

The elements of $S$ are assumed to follow an inverse-Wishart distribution centered at $2 * 10^{-3}$ times the prior mean(s) of the relevant element(s) of the vector $\alpha_{t}$ with the prior degrees of freedom equal to the minimum allowed. The prior covariance matrix for the state innovations, $Q$, is set to $5 * 10^{-4}$ times the OLS estimate over the training sample and thus is less infomrative than in Cogley and Sargent (2005) and Primiceri (2005). The priors for all the other hyperparameters are borrowed from Cogley and Sargent (2005). We use 100000 Gibbs sampling replications, discard the first 80000 as burn-in. 


\section{Newey-West's adjustment as function of lag trun- cation}
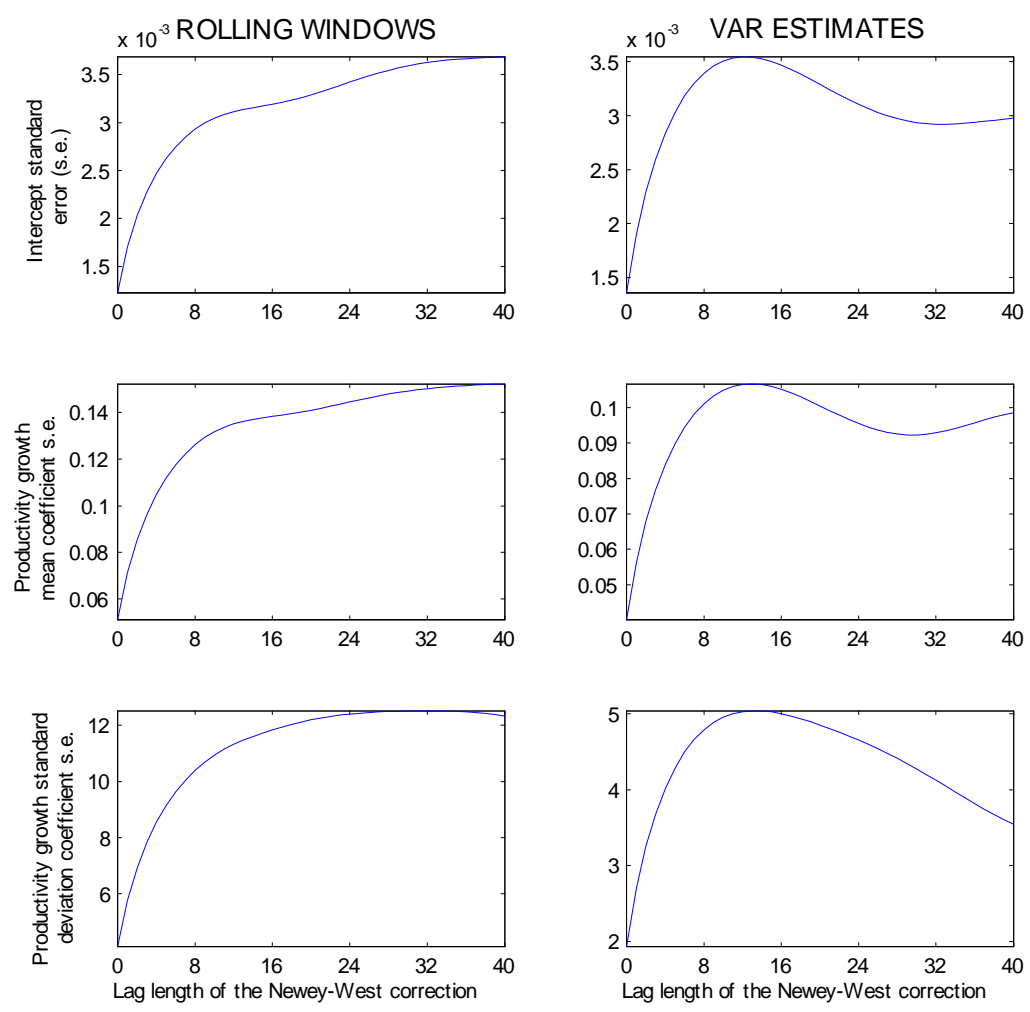

Figure 8: estimated standard errors of the coefficients in the linear model as a function of the lag truncation $q$ in the adjustment formula proposed by Newey and West (1987). 